\title{
NO UNA, SINO MUCHAS
}

\section{CIUDADES}

\section{ENTREVISTA A ÓSCAR}

\section{LIMACHE}

Fabio Esteban Cabrera Morales*

fabio.cabrera@pucp.pe

Pontificia Universidad Católica del Perú

Resumen: Han pasado muchos años desde que se publicó el libro Viaje a la lengua del puercoespin (1989). Óscar Limache presenta en sus poemas la búsqueda de su propio lenguaje lírico, a través de un viaje literario por infinitas "ciudades invisibles", en las cuales, no obstante, emerge una ciudad en los horizontes de sus habitantes: la capital peruana. A continuación, presentamos una conversación con el poeta en el año 2013.

Palabras clave: Poesía peruana, Lima, ciudades, década de 1980.

NOT ONE, BUT A LOT OF CITIES. INTERVIEW WITH ÓSCAR LIVACHE

Abstract: Certain time has passed since Oscar Limanche first published Viaje a la lengua del puercoespin (1989). Through his poetry, the author gives testament of the search of an original lyrical

* Fabio Esteban Cabrera Morales es estudiante de Historia en la Pontificia Universidad Católica del Perú. Ha sido ponente en el Coloquio de Estudiantes de Historia PUCP, en su edición 2016, y en el Coloquio de Estudiantes de Antropología de la misma universidad. En estos eventos, sus investigaciones han versado sobre Etnohistoria e Historia Política del siglo XX. Actualmente es miembro del grupo de voluntariado e investigación "Historia para Maestros". 
language as can be seen in the literary journey he takes us in through the endless and timeless "invisible cities". In the latter, however, emerges a city on the horizon of its dwellers: the Peruvian capital city. The following is an interview with the poet from 2013.

Keywords: Peruvian poetry, Lima, cities, 1980's.

Tacido en Lima en 1958, además de educador y traductor, Óscar Limache destaca 1 como poeta. Ha publicado diversas antologías y dos poemarios: Viaje a la lengua del puercoespin y Vuelo de identidad. Con el primero obtuvo el Premio Copé de Oro de Poesía en 1988 y ha tenido cinco ediciones, dos en el Perú y tres en el extranjero (Lima: Ediciones Copé, 1989; Lima: Lluvia Editores, 1994; La Habana: Editora Abril, 2002; México: Linajes Editores, 2008; Lima, Santiago de Chile: Amotape Libros / Andesgraund Editores, 2016). La siguiente entrevista es, principalmente, sobre su primer libro de poemas.

Viaje a la lengua del puercoespín llegó a mis manos en el año 2009, cuando cursaba el segundo año de media. Limache, que fue mi profesor de Lectura en los cinco años de mi secundaria, invitó a todos los alumnos a la presentación de una nueva edición de su poemario en la feria del libro de mi colegio. Al volver a casa, con el libro autografiado, cuya dedicatoria poseía un aire de bienvenida a la poesía, se había producido en mi cabeza el prejuicio de que no entendería nada del poemario. En efecto, mis prejuicios se cumplieron: no entendía por qué había textos de líneas tan cortas y por qué estaban, algunos de ellos, en desorden posicional, y por qué en un poema sobre una ciudad se abordaba otros temas no expresados en el título. Me pareció entrar en otro idioma y hasta en un universo distante, alejado totalmente de cualquier lenguaje explícito.

Ya en cuarto año de secundaria, por el mismo cronograma y plan de estudios en los cursos de Literatura y Lectura, empezamos a leer y a estudiar el campo lírico, principalmente contemporáneo. No obstante, aunque empecé en los siguientes meses a adoptar a la poesía como un vicio, aún persistía un problema: no entendía los poemas, por lo menos no en su totalidad. Así que opté, para que mi reciente y novato vicio no concluyera, por un remedio puntual, similar a una anestesia: darle mi propia interpretación a versos ajenos.

Transcurrido más de un año, ya en la universidad, tenía que entrevistar a un poeta peruano sobre su poemario principal como parte del trabajo final del Taller de Poesía dictado 
por Victoria Guerrero. No se me ocurrió otro poeta que Limache. Conversé con él y aceptó ser entrevistado. El problema volvía a ser su poemario. Le había dado varias lecturas a lo largo del 2012 y parte del 2013 (interrumpidas abruptamente por los textos académicos) y había logrado zambullirme en ese viaje hacia la lengua del puercoespín; pero cuando volvía de la travesía lo hacía con varias dudas y algo disconforme con mi propia lectura. Sin embargo, el viaje se volvía cada vez más digerible, sobre todo cuando lo leía en el bus rumbo a la universidad, en los laberintos del principal lugar del que habla el libro: en Lima.

Haré una pregunta tal vez muy obvia, pero necesaria para empezar el diálogo, ¿por qué el nombre de Viaje a la lengua del puercoespín?

Hay un texto de Odysséas Elitis, el poeta griego, que dice:

\author{
"Ves dijo ellos son los Otros \\ y los debes afrontar a toda costa \\ si deseas que tu forma indeleble \\ se mantenga como es \\ Porque muchos llevan la camisa negra \\ y otros hablan la lengua del puercoespín...”
}

Este libro es un viaje en busca de mi propio lenguaje poético, reconociendo todas mis influencias literarias y tratando de acercarme y diferenciarme al mismo tiempo de esa lengua afilada, ríspida e hiriente que usan los habitantes de mi ciudad (los "Otros" del poema de Elitis).

¿Qué relación puede tener eso con los lugares descritos en la primera parte del poemario?

¿Qué encuentras tú en la primera parte del poemario...? 


\section{Ciudades diversas...}

Y dime, ¿quién habla en esas ciudades?, ¿cuál es el "yo poético” ahí?

Esa era una de las preguntas: ¿cuál es el "yo poético"? Al parecer, usted se pone en el lugar de otras personas, incluso hasta el "yo poético" figura en plural.

Así es, y se puede deducir eso porque en algunos casos habla un viejo; en otros casos, habla un niño, una mujer, una vieja, una prostituta. Claro, hay un "narrador" colectivo también, hay un "nosotros". Entonces, no es la voz del autor la que está hablando ahí, sino distintas voces. Más aún, hay una cita de Mirko Lauer, casi al final del libro, que habla de las mil voces que suman y conforman el libro y de mi esperanza en que, a través de esas voces, pueda mantenerse mi voz:

"Sólo la distorsión que produce la voz de mil seres humanos puede mantener intactas mis palabras".

Todas las citas apuntan, más o menos, a la misma situación, y los epígrafes también, ya que forman parte esencial del texto.

Con eso se refiere al primer poema, el que es como un "collage", porque al llegar al final, me di cuenta de que eran citas unidas de otros autores.

Exacto, solamente que al comienzo parece que fuera un poema coherente, porque es coherente; pero, ¿quién le dio esa coherencia? El autor que hilvanó versos de autores disímiles en un solo texto, en un centón, un poema que se construye con fragmentos de otros, y ese "centón" indica al lector desde el inicio que todo lo que va a leer es un gran "collage".

\section{Abora, ¿qué papel cumplen los dibujos y qué significan?}

Veamos, ¿hay algún dibujo que represente animales o personas? 
No, no be visto...

Pues, no hay. ¿Qué tienen en común todos los dibujos?

Mapas, ciudades...

Sí, son mapas, son ciudades. El poemario se titula Viaje a la lengua del puercoespin; la primera parte se llama "Las ciudades invisibles" y la otra, "La loca alacrán y otras historias de Lima", por ende, esos mapas ¿qué podrían significar...? Ahora, es un libro de viajes que habla de "ciudades invisibles", ¿qué has descubierto?

Tal vez son mapas que tienen que ver con esos lugares, aunque no son muy claros. Hay un mapa de una ciudad amurallada y hay también uno en el que figura un círculo dividido entre Europa, Asia y África.

Así es.

Me pareció leer alguna vez que usted nunca había visitado esos lugares, ¡es cierto eso?

Sí, es cierto; por eso son “invisibles”. Es más, aún no los he visitado y, probablemente, nunca lo haga.

Entonces, ¿cómo se fueron formando estas “ciudades invisibles” en su vida, tomando en cuenta que nunca estuvo en ellas?

Tendríamos que partir de la siguiente pregunta: ¿en qué momento uno puede decir que conoce una ciudad? La respuesta más sencilla es "porque estuvo ahî". Hay gente que ha estado parada en Nueva York o en Buenos Aires y no conoce la ciudad, sin embargo, ha estado allí; puede haberla caminado una semana y no por eso la conoce. Alguien que haya vivido toda su vida en Lima, ¿necesariamente conoce Lima? Habría que preguntarse lo siguiente: ¿de dónde surge "el conocer una ciudad”? ¿Es solamente el "estar ahî”? ¿O también el conocimiento parte de haber leído todos los libros acerca de una ciudad, haber 
visto películas filmadas en esa ciudad, haber escuchado todas las canciones que esa ciudad inspiró, haber recolectado todas las menciones literarias que hay sobre esas ciudades en el mundo, sobre París, sobre Nueva York, sobre Roma? Entonces, ¿se puede escribir sobre una ciudad que uno no ha visto? Fue la pregunta inicial que yo me hice y la respuesta es este libro.

Es decir, que sí se puede conocer una ciudad sin haber estado alli...

No lo sé. ¿¿uién puede decir que "conoce” una ciudad?

Bueno, creo que la gran mayoría de amigos limeños que tengo, y por supuesto que viven aqui, no conocen Lima...

Exacto, y yo, que conozco a varios de tus compañeros del colegio, sé que no conocen Lima, que no podrían sobrevivir porque no conocen las calles y sé que se perderían.

Cambiando de tema, ¿fue solo la literatura lo que lo llevó a conocer esas "ciudades invisibles"?

No. También fue el cine, conversaciones, noticias periodísticas, juegos, cartas que me mandaron de esas ciudades gente de la cual yo conocía a través de la correspondencia en inglés, y muchos de los poemas son copia textual de las cartas que me enviaron y, más de treinta y cinco años después, todavía las conservo. Sirvieron de germen para todo eso.

¿Por qué hay ciudades que se repiten, como Nueva York o Roma?

¿Qué interpretación le puedes dar a esa repetición...?

Creo que va por el lado de que, tanto Nueva York como Roma, necesitaron más que un poema para describir las perspectivas que usted tenía sobre esas ciudades... 
Sin embargo, cada uno de los tres poemas de Nueva York y los dos de Roma tocan temas distintos... Ahora, ¿por qué esas dos ciudades y no ciudades más grandes como París, Los Ángeles, Pekín, que tendrían más historias, tienen solamente un poema y las dos primeras tienen más? Debe de haber alguna explicación para todo ello...

Por ejemplo, en un poema tilda a Roma como la "ciudad perfecta"...

Así es...

¿Por qué sería la ciudad perfecta para usted?

¿Y para ti qué sería una ciudad perfecta?

No creo que la haya, pero mi pregunta es si fue por los temas la cantidad de poemas de esas ciudades o por otro aspecto...

En realidad fue por el significado que tienen esas ciudades. ¿Qué es Roma? ¿Qué fue Roma?

La ciudad más importante del Imperio romano, la ciudad más importante de la Antigüedad se podría decir...

Así es. Todos los caminos conducían a Roma. Si ves el mapa que está al costado del poema de Roma se aprecia que hay caminos y todos llegan a un solo punto, pero no es Roma. Todas las "ciudades invisibles" conducen a una sola ciudad, que no es Roma tampoco y que sistemáticamente no está mencionada...

¿Lima...?

Es Lima. 
Eso es, porque también he dejado regadas pistas a lo largo del libro, hay muchas claves; creo que eso es bastante claro. $Y$ ese verso que mencionas, y que tan bien recuerdas, está incluido en una de las tres "Nueva York", ¿y qué es Nueva York para el mundo actual? La capital del mundo. Más aún, en uno de los poemas "Nueva York” es Melville el que habla y en otro es García Lorca...

“No es necesario viajar! El mundo es Lima”...

Ajá, ese es Melville. Y Whitman y Lorca están juntos también en un poema de Poeta en Nueva York, libro que cuando terminé de leerlo generó en mí el deseo de escribir algo equivalente para Lima, eso es Viaje a la lengua del puercoespin. Claro, los abismos son tremendos, es evidente que yo no soy Lorca, y que Lima no es Nueva York; pero en mi libro aparece "Nueva York" tres veces, y en una habla Lorca. En "París", por ejemplo, habla Vallejo...

El que está describiendo al comienzo a París es Vallejo, ¿no?...

Sí, el libro tiene ese tipo de referencias.

En el poema "Nueva Jersey", ¿a qué se refiere con "China cubana"?

Ahí menciono un maestro. La salsa nace o se difunde desde Nueva York y llegaba hasta Nueva Jersey, que está al otro lado del río Hudson, donde viven muchos peruanos, entre ellos, concretamente, un amigo mío salsero. Entonces, yo estoy hablando del nacimiento de la salsa y de una de las piezas musicales que a mí más me conmueven: "China cubana” de Willie Colón. Todo salsero identifica ese texto...

Bueno, yo no soy salsero, aunque sí me gusta la salsa...

Hay que ser ciudadano del mundo.

Otra curiosidad: en el poema "Estocolmo" se hace mención a que Antonio Cisneros ganaba el Nobel en el año 2000, ¿era un deseo que usted tenía, una posibilidad de que un poeta peruano ganara el Nobel o había otra razón? 
No, no era eso; era una broma, era un juego irónico. Así lo entendieron muchos lectores; no obstante, Toño lo entendió como un homenaje; luego le dijeron que era una ironía y se molestó, hasta me quitó el saludo por un tiempo. Luego parece que ya no le importó mucho y se volvió nuevamente amigo mío y, bueno, es un homenaje a Toño, un personaje egolátrico...

\section{Pero podrían ser las dos cosas también, un homenaje y a la vez una broma...}

Sí. Un texto puede ser ambas cosas al mismo tiempo. A mí me gusta la poesía de Cisneros, desde siempre me ha gustado, pero también su ego era muy grande. Entonces, yo bromeo con él, ilustro, más o menos, cómo respondería él a una entrevista luego de haber ganado el Nobel, “¿Y maestro cómo le va con el frío?”, pregunta el supuesto entrevistador. Y él, a pesar del frío en Estocolmo, está feliz, por la manera en que responde. Por supuesto, algún peruano en algún momento tenía que ganar el Nobel; se demoró diez años más, pero así fue.

\section{En el poema "Melbourne" hace una mención a un competidor olvidado que quedó en segundo lugar, ¿quién fue o cuál era la idea del poema?}

No sé quién fue, porque nadie lo recuerda. Yo no pensaba en nadie en especial, sino pensaba en el hecho de quedar segundo en cualquier tipo de competencia. Alguna vez en clase he preguntado quién fue el primer hombre en llegar a la Luna y todos responden que fue Neil Armstrong, y cuando les pregunto quién fue el segundo, el aula queda en silencio. Por ello, ganar un premio literario te vuelve relativamente famoso, pero al que queda segundo nadie lo recuerda; yo trasladé esas consecuencias a una situación hipotética de una olimpiada, la primera olimpiada que hasta ese momento se había realizado en el Hemisferio Sur era la de Melbourne; luego, y años después de que se publicara el libro, se realizó la de Sidney. Entonces, yo imaginaba el rencor que sentiría el que quedara en un segundo lugar, muriendo de rabia al ver cómo izaban la bandera del ganador y tocaban el himno de su país. En ese poema puse las palabras que el perdedor le va diciendo al ganador, mudo en realidad, porque no se entienden, no hablan el mismo idioma; por eso, al final concluyo: "lástima que nadie se acuerde de quien llegó segundo”. 
¿Qué lo motivó a colocar a Tunguska entre las “ciudades invisibles”, si es que no hay una ciudad?

Porque era la más invisible de todas. "No hay ciudad en Tunguska". Hay gente que se pasa buscando la ciudad en Tunguska, pero el poema, justamente, te habla de algo que no existe, de algo tan inaprensible, de algo que no se sabe qué fue pero sucedió.

El cometa que cayó en la Rusia zarista...

En la Siberia. Es decir, que todos los árboles hayan caído en una misma dirección significa muchas cosas; por ello, a mí siempre me interesó el hecho de que el conocimiento a veces parte no del suceso real o directo, sino de la lectura de su huella. O sea, es la huella de lo que sucedió en Tunguska lo que ha generado la explicación de lo que pudo haber sucedido, no porque alguien haya estado allí, nadie estuvo allí.

\section{Abora, en el poema "Ginebra” usted hace una afirmación que me llamó mucho la atención: "También son las mujeres ciudades invisibles". ¿Qué quiso decir con ello?}

Hay ciudades con nombre de mujer y hay mujeres con nombre de ciudad; Atenas, por ejemplo, Florencia. Ginebra es también un nombre de mujer. Era la esposa del rey Arturo, asediada por sir Lancelot, uno de los caballeros de la Mesa Redonda. Ginebra es una mujer, pero también es un licor y una ciudad. Así como esta ciudad es una mujer, también son las mujeres ciudades invisibles, nunca alcanzamos a verlas, a entenderlas, a conocerlas por más que estemos ahí con ellas, por eso tienen nombres de ciudad y las ciudades tienen nombres de mujer. Además, es una alusión a Las ciudades invisibles de Calvino, donde cada ciudad tenía nombre de mujer... Mi libro es una invitación a leer otros libros.

Al fin y al cabo, ¿cree que es Lima una ciudad que posee más imaginarios que las "ciudades invisibles"?

De hecho. Si no lo creyera no le hubiera dedicado un libro. Además, en casi todas las “ciudades invisibles" son limeños los que están hablando, hasta son limeños los protagonistas 
de las obras mencionadas ahí y los que son extranjeros están hablando de Lima en todo momento...

Y los peruanos de otras ciudades también hablan de Lima, como Gonzalo Rose...

Sí, por ejemplo.

Su perspectiva sobre nuestra capital es distinta, por ejemplo, a la del grupo Kloaka, ¿qué cree que le dio a usted Lima que a ellos no, para tener una visión no negativa sino compleja?

En primer lugar, ¿`cuál sería la visión del grupo Kloaka?

De lo que he leido, es que tienen una visión sobre Lima, digamos, decadente, tétrica...

Esa ciudad, que antes de Kloaka es descrita por Verástegui y los del grupo Hora Zero, es la que yo también he vivido pero como limeño, ya que ellos en su mayoría eran de provincia. Yo he andado por las mismas calles que ellos, he olido los mismos olores a orines que ellos, he caminado sobre la misma basura que ellos caminaron. Lima los trató a ellos de una manera. Estoy seguro de que al haber pasado por lo mismo me ha afectado igual o peor porque es mi ciudad natal. Pero no parece que en mis poemas haya esa perspectiva decadentista, aunque tampoco hay una visión optimista como si fuera la mejor ciudad del mundo, sencillamente no hay ciudad, no describo calles, no digo "estoy caminando por Colmena, ahora entro al Parque Universitario", como, por ejemplo, sí lo hacían los poetas de Hora Zero, ellos sí describían calles, lugares, bares. Los bares de Hora Zero los he conocido y los de Kloaka también, incluso he ido a tomar con ellos, soy amigo de ellos; pero no era eso lo que yo quería mostrar, tampoco lo quería ocultar porque aflora en varios poemas; ahí hay borrachos, prostitutas, asesinos...

Como en "Nocturno de la avenida Inca Garcilaso de la Vega (antes Wilson)", "Camino con los hígados al viento..." 
Claro, ahí ya no es decadente, sino apocalíptica, es el fin, todo se acaba. Al personaje se le van destruyendo cosas, partes del cuerpo, y sigue caminando. Es como una persona que va hablando en medio de las explosiones. Pero, en fin, me alegra que descubras que no hay decadentismo, mas sí visiones oscuras, casi todo sucede de noche...

\section{Como el "Niño cruzado de electrones"...}

El "Niño cruzado de electrones" muere en la Plaza San Martín, es un niño real. La "Razón de desalojo" es un desalojo real. "Un golpe de omóplato" es una caminata real en Lima...

\section{“La loca alacrán”...}

"La loca alacrán" era una loca que ocupó un terreno vacío al costado de mi casa y prendió fuego a todo; hasta tuvieron que llamar a los bomberos. Todos esos personajes son reales pero están transformados por una especie de visión febril o alucinada; el "yo poético" está afiebrado y va describiendo una ciudad de locura, que además termina en el "Inicio", donde son unos locos los que hablan y son los personajes de No una, sino muchas muertes de Congrains. En realidad, veo que este libro es para un lector de Lima. No es un libro fácil, no pretendí hacerlo fácil; pero tampoco pretendí hacerlo difícil. Sencillamente quise que dijera exactamente lo que yo quería decir; en general, el libro está tal como yo quería que saliera; si no, no lo hubiera sacado tampoco: los mapas son esenciales al texto, las citas igualmente. Solamente hay que leer con cuidado la estructura porque es circular, el libro comienza y termina igual. La última frase invita a volver empezar todo de nuevo. Yo creo que esa construcción formal del libro debe ser leída también y no ha sido leída aún. Es que en realidad la gente no lee esas cosas.

\section{El poemario tiene dos partes, ¿cómo se entrelazan?}

Yo estaba escribiendo dos libros distintos, Las ciudades invisibles era uno y La loca alacrán y otras historias de Lima era otro, pero descubrí en algún momento que me hacía muchas preguntas en el primero y que en el segundo poemario yo respondía a esas preguntas sin habérmelo propuesto y, cuando encontré las citas claves, quedaron unidos; por eso tienen 
dos estilos distintos. La primera parte está llena de preguntas y la segunda llena de posibles respuestas.

Por último, ¿cuánto tiempo le tomó hacer el poemario?

Once años de escritura...

¿Pensaba de todas maneras en mandarlo a un concurso primero o publicarlo antes...?

Sí, jamás lo iba a publicar yo mismo, a diferencia de mis colegas que se consideraban poetas y publicaban por esos tiempos ellos mismos sus libros. Yo trabajaba en una editorial y podía haberlo hecho, pero quería, sobre todo, que gente que desconocía quién era el autor valorara el libro o lo "destruyera". Lo mandé al Copé en el año 1986 y obtuve la primera mención honrosa, era la tercera bienal de poesía; eso me dio la clave de que no estaba mal lo que estaba escribiendo. Dos años después se había duplicado el número de poemas en las dos partes del poemario, lo mandé nuevamente y gané el Copé de Oro. Por cierto, antes de la publicación consulté si podía agregar unos poemas más, me dieron un límite y sumé algunos; sin embargo, unos siete u ocho poemas quedaron fuera por falta de tiempo, los cuales decidí no incluir en las nuevas ediciones de mi libro; poemas que también podrían dar otras claves para la lectura del texto, pero que ya pasaron al olvido. 